\title{
FACTORS AFFECTING DELAY IN DIAGNOSIS OF COLORECTAL CANCER: A CROSS-SECTIONAL STUDY; FROM TERTIARY CARE HOSPITAL OF KARACHI PAKISTAN
}

\author{
Rubab Nafees Ahmed ${ }^{1}$, Lajpat Rai ${ }^{1}$, Khursheed Ahmed Samo ${ }^{1}$, Summaya Saeed ${ }^{1}$, Ammara \\ Salam $^{2}$, Hina Khan ${ }^{1}$, and Amjad Siraj Memon ${ }^{1}$ \\ ${ }^{1}$ Dow University of Health Sciences \\ ${ }^{2}$ Fazaia Ruth Pfau Medical College
}

April 20, 2021

\begin{abstract}
Background: CRC incidence is increasing in our region. There is no specific CRC control program or national cancer registry in Pakistan. Previously no data has been published on presentation and diagnosis delay of CRC in our region. This study is conducted to determine the factor affecting delay in presentation and diagnosis and to provide baseline information to launch a CRC control program. Primary objective is to determine factor causing delay in diagnosis of CRC. Secondary objective is to evaluate relationship between tumor site and stage of CRC with presenting symptoms and symptom duration. Methods: This project is a prospective cross-sectional study on 113 biopsy-proven CRC patients admitted to the surgical ward of civil hospital Karachi. Results: A total number of participants was 113. Presentation delay was observed in $83.2 \%$ of patients. The main reasons for a reported delay in the presentation were lack of patients' knowledge that these symptoms may be cancer (60.4\%), the wrong diagnosis by the primary physician (34.6\%), or the patient didn't want to visit the doctor (0.04\%). Most tumors (95\%) originated from the sigmoid and rectum. $38.9 \%$ and $44.2 \%$ of the patients diagnosed at Stage 4 and 3 respectively. Conclusions: This study revealed that CRC patients in Pakistan are facing delays in presentation and diagnosis. This is the reason behind diagnosis at the advanced stage with a poor prognosis. Based on this study findings CRC control program should be introduced to detect CRC at an early stage. Keywords: Colorectal cancer, Colon, Rectum, Cancer, Presentation delay, Diagnosis delay.
\end{abstract}

\section{Hosted file}

Main Document.pdf available at https://authorea.com/users/409068/articles/518836-factorsaffecting-delay-in-diagnosis-of-colorectal-cancer-a-cross-sectional-study-from-tertiarycare-hospital-of-karachi-pakistan

\section{Hosted file}

Table.pdf available at https://authorea.com/users/409068/articles/518836-factors-affectingdelay-in-diagnosis-of-colorectal-cancer-a-cross-sectional-study-from-tertiary-carehospital-of-karachi-pakistan 